\title{
Conhecimentos tradicionais Kaingang nas terras indígenas Jamã Tÿ Tãnh/Estrela, Pó Nãnh Mág e Ka Mág/Farroupilha, Rio Grande do Sul/Brasil: permanências e (re)significaçōes no fio do tempo
}

Kaingang traditional knowledge in the indigenous villages Jamã Tỹ Tãnh/Estrela, Pó Nãnh Mág and Ka Mág/Farroupilha, Rio Grande do Sul/Brazil: permanences and (re) meanings passing the time

\author{
Marina Invernizzi \\ Juciane Beatriz Sehn da Silva \\ Luís Fernando da Silva Laroque
}

\section{Resumo}

Os Kaingang são uma etnia indígena do tronco linguístico Jê, estão localizados tradicionalmente no centro sul do Brasil Meridional e somam aproximadamente 38 mil indivíduos. Os espaços de investigação são a Terra Indígena Jamã Tÿ Tãnh, situada na cidade de Estrela/RS e as Terras Indígenas Pó Nãnh Mág e Ka Mág, ambas localizadas na cidade de Farroupilha/RS. O objetivo é apresentar alguns conhecimentos tradicionais perpetuados e/ou (re)significados pelos Kaingang das Terras Indígenas Jamã Tỹ Tãnh, Pó Nãnh Mág e Ka Mág em contextos urbanos. A metodologia consiste em um estudo qualitativo e descritivo. Os procedimentos metodológicos são revisão bibliográfica sobre os Kaingang, levantamento e análise de fontes documentais encontradas no Ministério Público Federal de Lajeado e de Caxias do Sul. Nas Terras Indígenas mencionadas foram realizadas pesquisa de campo, posteriores escritas de diários de campo, registros fotográficos e entrevistas com os indígenas baseadas na metodologia de História Oral. Os dados pesquisados foram analisados com base em teóricos da cultura, etnicidade, cosmologia e interculturalidade onde, por exemplo, a nominação das Terras Indígenas relaciona-se a ordem simbólica Kaingang. Jamã Tÿ Tãnh significa "os coqueiros que vivem ali", Pó Nãnh Mág significa "morros e montanhas próximos de nós" e Ka Mág "árvore grande que está aqui". Existe também, entre outros aspectos, a prática da reciprocidade intra e interaldeã, a organização sociopolítica, permanência de conhecimentos de etnobotânica e a pedagogia do afeto a terra que, portanto devem ser respeitados como direitos humanos e a ancestralidade indígena. 
Palavras-chave: Kaingang, Interculturalidade, Direitos, Terras Indígenas.

\begin{abstract}
Kaingang are an indigenous ethnic group of the Jê linguistic trunk, they are traditionally located in the southern center of Southern Brazil and total approximately 38 thousand individuals. The research areas are Jamã Tÿ Tãnh indigenous village, in Estrela city and Pó Nãnh Mág and Ka Mág indigenous village, located in city of Farroupilha (both in Rio Grande do Sul brazilian state). The objective is to present some traditional knowledge perpetuated and / or (re) signified by the Kaingang of the Indigenous Village, already mentioned, in urban contexts. The methodological procedures are bibliographic review about Kaingang, survey and analysis of documentary sources found in the Ministério Público Federal of Lajeado and Caxias do Sul cities. In the indigenous villages mentioned, field research, field diary writings, photographic records and interviews based on Oral History methodology were carried out. The results obtained were analyzed in theories of culture, ethnicity, cosmology and interculturality and demonstrate, for example, that the nomenclatures of the indigenous villages are of a symbolic logic characteristic of the Kaingang. Jamã Tÿ Tãnh means "the coconut trees that live there", Pó Nãnh Mág means "hills and mountains near from us" and Ka Mág "big tree that is here". There is also, among other aspects, the practice of reciprocity within and between interdependence, sociopolitical organization, the permanence of ethnobotanical knowledge and the pedagogy of affection for the land, so they must be respected as human rights and indigenous ancestry.
\end{abstract}

Keywords: Kaingang, Interculturality, Rights, Indigenous Villages.

\section{Introdução}

A região denominada atualmente como Vale do Taquari, situada na macrorregião nordeste do Rio Grande do Sul/Brasil, trata-se um tradicional território de ocupação indígena no passado. Destacase, nesse sentido, o estudo realizado por Sidnei Wolf (2012), que comprova a existência não só de grupos caçadores-coletores e Guarani, como também de populaçōes Proto-Jê na região em questão. Segundo Wolf (2012, p.169), foi uma "persistente ocupação sustentada por um sistema de assentamento composto por estruturas subterrâneas e locais com evidências líticas a céu aberto". Desta forma, a presença de sítios líticos próximos a lugares com estruturas subterrâneas, supōe a ocorrência de áreas de exploração para caça, coleta e pesca.

Destaca-se que, apesar da tentativa do governo da Província de São Pedro do Rio Grande do Sul, no século XIX, em aldear os Kaingang, inúmeros grupos destes indígenas permaneceram fora des- ses espaços que entendemos como pretensōes de confinamento. Além disso, o cenário que se desenha a partir do século XX é marcado pelo movimento de diversas famílias para fora destas áreas, tendo em vista dinâmicas socioculturais de parcialidades Kaingang e questōes de sustentabilidade que enfrentam.

Conforme indica Tommasino (2001), a partir dos anos 2000 ocorre uma intensa movimentação dos Kaingang em direção a outros espaços situados em contextos urbanos, dentro do seu tradicional território. Nesse contexto, insere-se a trajetória de diversos grupos Kaingang no Rio Grande do Sul que atualmente constituem Aldeias na região do Vale do Taquari, da Serra Gaúcha e da Grande Porto Alegre. Assim, temos a Terra Indígena Jamã Tÿ Tãnh, situada em Estrela, a Terra Indígena Foxá, em Lajeado, a Terra Indígena Pó Mág, localizada na Tabaí, as Terras Indígenas Pó Nãnh Mág e Ka Mág, ambas situadas em Farroupilha, a Terra Indígena Por Fi Gâ, em São Leopoldo, bem como 
a Terra Indígena Ỹmã Topẽ Pẽn, Ỹmã Fág Nhin, e Morro Santana, todas situadas em Porto Alegre.

Destaca-se que ao mover-se sobre/no seu território tradicional, os Kaingang continuam a vivenciar muitos de seus costumes antigos e outros tantos são (re)elaborados em contato com os não índios. O presente estudo tem por objetivo apresentar alguns conhecimentos tradicionais perpetuados e/ou (re)significados pelos Kaingang das Terras Indígenas Jamã Tỹ Tãnh, Pó Nãnh Mág e Ka Mág em contextos urbanos. Considerando que muitos desses conhecimentos, que representam suas cosmologias e foram aprendidos de seus antepassados, são mantidos nos lugares, em detrimento do conhecimento hegemônico, a problemática proposta que norteia a investigação é averiguar que embora impactados pelos projetos colonialistas ocidentais, em que medida os conhecimentos tradicionais indígenas são recorrentes de construçōes culturais e inerentes ao cotidiano Kaingang? A metodologia consiste em um estudo qualitativo e descritivo. Dentre os procedimentos metodológicos destaca-se a revisão bibliográfica sobre os Kaingang, bem como levantamento e análise de fontes documentais que se encontram junto ao Ministério Público Federal de Lajeado e de Caxias do Sul. Realizou-se também pesquisa de Campo nas Terras Indígenas, e observaçōes participantes com a elaboração de diários de campo, registros fotográficos e entrevistas com os indígenas baseado na metodologia de História Oral. As análises foram realizadas tendo por referência teórica estudos de Castro (2006), Tommasino (2001; 2004; 2005) e Geertz (1978), sobre cultura; Barth (2000), no que tange a abordagem sobre etnicidade; Rosa (2005), que trata, sobretudo, de cosmologia; e Sidekum (2003), que tratam de interculturalidade.

\section{Etnoconhecimentos vivenciados na terra indígena Jamã Tỹ Tãnh/Estrela}

Os Kaingang da Terra Indígena Jamã Tÿ Tãnh referem ao município de Santa Cruz do Sul/RS como sendo seu local de origem para os deslocamentos pelo Vale do Taquari. No contexto das décadas de 1960 e 1970 iniciou-se o processo de movimentação do patriarca Manoel Soares com suas esposas e filhos, em busca de sustentabilidade e do local onde Manoel teria suas raízes. Isto se deve, sobretudo, à memória das marcas deixadas pelos seus antepassados, em territórios da Bacia Hidrográfica Taquari-Antas. No relato de uma das filhas, teria sido em busca do local onde o pai tivera seu umbigo enterrado que o grupo iniciou a trajetória de retorno (SILVA; LAROQUE, 2012). Dessa forma, a memória constitui-se como elemento fundamental na busca deste lugar de origem, e marca a (re)localização do grupo no Vale do Taquari. Little (1994) afirma que a memória coletiva é uma das maneiras mais importantes, pelas quais os povos se localizam num espaço geográfico. Dessa forma, o processo de criar um espaço novo torna-se primordial e se dá, em parte, pela manipulação múltipla e complexa da memória coletiva no processo de ajustamento do local.

Cabe destacar que questōes pertinentes à cultura Kaingang, também motivaram o grupo a empreender estas movimentaçōes, como pode ser observado através do relato do interlocutor $\mathrm{EF}$, ao afirmar que "nóis se cansemo de tá morando lá, né, o cara cansa de tá morando lá, fomo saindo, se acampando pela bera das estrada, pros nosso artesanato" (EF, 28/07/2016, p.1). Ou na narrativa de uma das matriarcas ao se referir que "Nóis não ficava num lugar só! Tinha que anda caminhando pra lá e pra cá!" (EC, 17/03/2011, p.1). Tommasino (2001) reforça a condição histórica de mobilidade dos Kaingang, pois segundo ela mover-se sobre o espaço indicava uma relação com o território Kaingang, sendo que este precisava apresentar um ecossistema variado que garantisse a reprodução física e cultural dos grupos locais. Também para Cabral (2007), o espaço enquanto organização social, é marcado por complexas interaçōes que só podem ser vistas de forma dialética, tratando-se do caso Kaingang, estes estabelecem relaçōes simbólicas com o lugar. 
Verifica-se que este grupo mantém ligação com os Kaingang oriundos de outras Terras Indígenas do norte do estado, como Nonoai, Guarita e Cacique Doble. Alguns, inclusive, passam a estabelecer-se por semanas na Terra Indígena Jamã Tÿ Tãnh, a fim de visitar seus amigos e "parentes", ou/e para a venda de artesanato na região (DIÁRIO DE CAMPO, 03/12/2015). Embora os indígenas refere-se a esses visitantes como "parentes", percebe-se que não há uma ligação consanguínea entre eles, mas cultural. Ou seja, para os Kaingang "parente" diz respeito ao pertencimento ao mesmo grupo étnico (DIÁRIO DE CAMPO, 10/08/2016).

Castro (2006) enfatiza que é parente quem os indígenas acharem que é, pois parentesco inclui afinidade e comensalidade, situaçōes que observamos entre os Kaingang da Jamã Tÿ Tãnh. O autor explica que as relações de afinidade são, em muitas culturas ameríndias, transmissíveis entre geraçōes, e na atualidade representa o arcabouço político e a linguagem ideológica dominante nas comunidades indígenas. Corrobora com essa questão os estudos de Sidekum (2003, p.292), ao afirmar que "As culturas desenvolvem-se sempre em condiçōes contextuais determinadas, como processos abertos, em cuja base se encontra o princípio do tratamento, da interação, e do comércio para com o outro". Para os Kaingang da Jamã Tÿ Tãnh, a prática da sociabilidade é marcada pela experiência de estar em contínuo trânsito.

Em 2013, por uma decisão do coletivo Kaingang é que a Terra Indígena passou a denominar-se "Jamã Tÿ Tãnh", significando "Morada do Coqueiro", ou "Aldeia do Coqueiro" (SCHWINGEL et al, 2014). Isso se deve ao fato de haver na área da Aldeia inúmeros coqueiros, que possuem grande importância cultural e simbólica para esse grupo.

A Aldeia nova, resultante de medida compensatória da duplicação da BR-386, entregue em 2015 à comunidade Jamã Tÿ Tãnh, é formada por 29 casas, uma escola e uma Casa de Fala (SILVA, 2016). Embora as casas sejam de alvenaria, vemos na conjuntura do espaço a pre- sença de alguns complementos feitos com uma estrutura de madeira, que servem para abrigar o fogão a lenha, o forno de barro ou mesmo o fogo de chão, bem como a presença de chão batido, mantendo a prática de cozinhar, conversar e socializar-se ao redor do fogo. Rogério Rosa (2005), ao explicitar sobre os três níveis que permeiam o território xamânico Kaingang, dentre os quais destaca-se o nível embaixo da terra, o nível mundo do alto e o nível terra, pontua, sobre este último, que é nele que desenrolam as relaçōes sociológicas dos Kaingang. O nível "terra" é constituído por três domínios hierarquizados: a "casa", o "espaço limpo" e a "floresta virgem". De modo simplificado, a "casa" é o espaço de moradia marcada por fronteiras internas (o canto do fogo, o local de confecção do artesanato) e externas (casa de fogo, fonte de água, roça). O "espaço limpo" é o local onde constroem suas casas e tem como fronteiras o cemitério, a lavoura, a escola, e todas as construçōes dos fog (brancos) que circundam o espaço demarcado pelos indígenas para morar. Já o domínio "floresta virgem" corresponde ao local em que habitam os animais e os espíritos (ROSA, 2005).

Em uma das casas, onde se procedeu a construção de um fogão de barro, conferiu-se que nesse espaço a família assa alguma caça que consegue nos matos próximos (tatu, lagarto, ouriço). Tal prática é realizada pela família por acreditarem que cada animal traz algum benefício para a sua vida, por isso a importância de comê-los, mesmo que esporadicamente. Revelam ainda que alguns animais ingeridos fazem com que eles "durem mais", que "vivam por mais tempo", e outros Ihes dão "mais agilidade" (DIÁRIO DE CAMPO, 14/01/2016, p.3-4).

Entre os Kaingang da Terra Indígena Jamã Tÿ Tãnh os alimentos cultivados por algumas famílias são compartilhados com as pessoas da comunidade, havendo nesse sentido, a ideia de reciprocidade e troca entre elas (DIÁRIO DE CAMPO, 10/08/2016). No que diz respeito ao tipo de cultivo praticado, destaca-se o milho, a mandioca e saladas tradi- 
cionais, alimentos próprios da cultura Kaingang (DIÁRIO DE CAMPO, 14/01/2016).

Verifica-se uma estrutura política hierarquizada em que a posição máxima dessa hierarquia é ocupada pelo(a) cacique, seguida do(a) vice-cacique. As atribuiçōes do cacique e do vice-cacique envolvem, tanto a representação da coletividade junto ao mundo dos brancos, quanto as decisōes sobre diversos aspectos da dinâmica interna do grupo. Estes, por sua vez, são auxiliados em suas tomadas de decisōes por outras representatividades, uma espécie de "conselho", que possui funçōes específicas relacionadas ao controle social, tais como brigas internas e bebedeiras, reservado aos chamados "delegados" e "cabos", ou aos processos de tomada de decisão e aconselhamento, auxiliado pelos chamados "capitão" e "conselheiro". Cabe ao cacique escolher os membros que irão compor a sua liderança (SILVA, 2016).

A pedagogia do afeto à terra é vivenciada na Terra Indígena Jamã Tÿ Tãnh, no cotidiano das relaçōes que o grupo estabelece em sua interação com a Terra-mãe, o que pode ser percebido de diferentes formas, seja através da prática de enterramento do umbigo, do não uso do agrotóxico em suas plantaçōes, das brincadeiras das crianças em contato direto com a terra. Quando uma criança nasce, a avó ou uma pessoa mais velha é quem decide onde deve ser enterrado o umbigo e depois que a criança cresce, revela-se o "seu lugar no mundo", e o que se pediu à Terra-mãe: que seja um grande guerreiro, que resista a luta do povo. Esse lugar passa a ser o local onde está a raiz daquela pessoa, enquanto parte integrante do povo Kaingang (SCWHINGEL et al, 2014).

O afeto à terra também pode ser observado no relato do interlocutor EG, quando questionado sobre a relação dos Kaingang com a terra, ele destaca que "a terra pra nóis é a nossa mãe né! Ela é a nossa mãe porque ela nos cria, ela que nos dá sustentabilidade sobre o fruto, aonde nasce o mato nativo que dá fruto, é dela que nasce todo o nosso sustento" (EG apud SILVA, 2011, p.62). Ilustra esta concepção, a constatação de Seeger e Castro (1979), ao afirmar que a terra para as sociedades indígenas não poderia ser definida nunca como uma mercadoria, assim como não poderia ser entendida como um espaço homogêneo e neutro, mas era compreendida como um mosaico de recursos.

No entender dos Kaingang, terra, solo e território tribal são denominados " $G a$ ", que representa o lugar onde a pessoa indígena se realiza, enquanto sociedade específica, fundada num espaço físico, social e simbolicamente transformado. A concepção Kaingang de terra tradicional e de território possui uma dimensão mítico-cosmológica (TOMMASINO, 2005). Ga, reúne um conjunto de elementos naturais e sobrenaturais, reconhecidos como próprios de uma terra tradicional Kaingang. Sob essa ótica, pode-se afirmar que a terra ocupa um lugar primordial na vida Kaingang. Além de necessitarem dela para a manutenção material e simbólica, os Kaingang, segundo seu mito de origem e sua cosmologia, nasceram da terra, por isso a consideram "Māe".

Na área atual da Terra Indígena Jamã Tÿ Tãnh existe uma pequena área de mata com espécies nativas e exóticas, de onde retiram matéria-prima para a confecção do artesanato, coletam plantas que são usadas como remédio e aproveitam as árvores frutíferas (DIÁRIO DE CAMPO, 07/07/2016). Essa área corresponde ao termo cultural "mato virgem" de que nos fala Almeida et al (2009) e é de grande importância para essa comunidade indígena. Vemos essa concepção de forma contundente no relato de nosso interlocutor EA:

Pra nóis essa área de mata tem toda a importância, não deixemo nem eles meche ali, inclusive eles tavam querendo faze uma estrada assim, mais queriam tirar um pouco da metade, aí nóis falemo não, não tira não, porque isso daí é o nosso mato, é onde nóis vivemo, deus o livre se tira essas mata aí, pra nóis é ouro, bem dize, essa mata pra nóis é ouro e daí tem a sanga que passa ali, onde as crianças podem agora toma banho, ali, a vontade, mais perto (EA e EB, 10/02/2016, p.4). 
Conforme Kimiye Tommasino (2004), na concepção Kaingang, cada ambiente é habitado por seres naturais e sobrenaturais. Também, as matas abrigam animais, vegetais e seres sobrenaturais. Embora não nos tenha sido revelado no relato anterior, acreditamos que a defesa da mata e sua associação com algo muito precioso por parte do interlocutor EA, deve-se a presença do que Tommasino refere, na língua Kaingang, como o nem tãn, ou seja, o "espírito guardiāo". Assim, a mata que abriga a sanga constitui espaço de representação sócio-simbólica, na medida em que representam espaços onde os Kaingang continuam mantendo suas relações culturais com o ambiente, aspecto que precisa ser respeitado como direito tradicional de um povo indígena.

Os Kaingang da Terra Indígena Jamã Tÿ Tãnh revelam que a terra e a água têm sido muito massacradas, devido ao uso de agrotóxicos nas plantaçōes que circundam a Aldeia, o que acaba afetando a vida da natureza como um todo, por conseguinte, dos Kaingang que se veem como parte dessa natureza. Nesse sentido, o entrevistado EF revela que "Primero quando nóis vinha, nóis pegava bastante peixe, agora nóis não tamo pegando mais nada de pexe. Não dá, por causa dos veneno, dos tóxico, mata tudo!" (EF, 28/07/2016, p.6). O tempo, a que se refere nosso sujeito da entrevista, é o tempo wãxi presente em sua memória, quando era criança e os peixes ainda eram abundantes.

Tanto o córrego que corta a área indígena, quanto a pequena área de mata que permeia o nível "terra", constituem-se como espaços onde no "tempo atual" (ūri) os Kaingang da Terra Indígena Jamã Tÿ Tãnh vivem o "tempo passado" (wãxi), pois ainda desenvolvem suas atividades de caça, coleta e pesca, embora que de forma esporádica e bastante limitada. Nesse espaço, vivem com os animais, vegetais e seus espíritos, com o mundo natural e sobrenatural. São espaços repletos de plantas medicinais, dos quais retiram matéria-prima para a confecção de artesanato, coletam frutos e alimentos tradicionais como o fuá e o raditi, onde banham-se, nadam, brincam inclusive de construir os pari (armadilhas de pesca) na sanga (DIÁRIO DE CAMPO, 14/01/2016; SCHINGEL et al, 2014). Quando estão no mato, os Kaingang sentem-se como "indígenas", num sentido profundo de "ser em essência". Na mata, reatam os laços com o natural e o sobrenatural, com o universo encantado que receberam de seus ancestrais (TOMMASINO, 2004).

O conceito de ecologia profunda, abordado por Fritjof Capra (2006) em seu estudo, parece pertinente para pensar a relação que os Kaingang estabelecem com a 'natureza'. Segundo o autor, a ecologia profunda - em contraposição à ecologia rasa que é antropocêntrica e centralizada no ser humano - não separa seres humanos ou qualquer outra "coisa" do ambiente natural. Ela vê o mundo como uma rede de fenômenos que estão fundamentalmente interconectados, reconhece o valor intrínseco de todos os seres vivos e concebe os seres humanos apenas como um fio particular na teia da vida.

Nesse contexto de 'ecologia profunda', os Kaingang possuem uma visão alicerçada na experiência e na vivência espiritual, de que a natureza e o "eu" são um só, ou seja, há uma ligação em tudo. Em suma, na ecologia Kaingang da Terra Indígena Jamã Tÿ Tãnh, há uma profunda relação de cuidado, respeito e interligação com a Terra-mãe, e ainda, embora seja pequena a área de mata que permeia a área da Aldeia, nesse espaço eles continuam a explorar os recursos da mata e vivenciar seus etnoconhecimentos de botânica, sobre os ciclos de reprodução dos animais e vegetais, e com os espíritos da mata.

\section{Aspectos kaingang nas terras indígenas Pó Nãnh Mág e Ka Mág}

A história dos Kaingang que atualmente vivem nas Terras Indígenas Pó Nãnh Mág e Ka Mág está relacionada as tradicionais ocupaçōes em espaços localizados em territórios da Bacia Hi- 
drográfica do Caí. A Terra Indígena Pó Nãnh Mág, surge no ano de 2006 e está localizada no Bairro Nova Vicenza, próximo à Balneária Nova Santa Rita em Farroupilha, Rio Grande do Sul (INVERNIZZI, 2015). Vale salientar que há registros históricos indicando que os espaços localizados entre as bacia hidrográfica do Taquari-Antas e do Caí, são parte do tradicional território Kaingang, portanto estima-se que o conhecimento dessas áreas não seja algo recente e sim permeado pelo processo de ensinamento entre as geraçōes.

Seguindo os estudos de Little (2002), outro elemento fundamental dos territórios sociais é encontrado nos vínculos sociais, simbólicos e rituais que os diversos grupos sociais diferenciados mantêm com seus respectivos ambientes biofísicos. Tomando os estudos de Little (2002) e aplicando ao caso Kaingang verificamos que a identificação territorial deste grupo perpassa os valores simbólicos interligados ao reconhecimento ambiental do espaço em que vivem. O que contribui para isso é o relato do E1A, que segue:

Eu pude entender, sendo encaminhado, tudo intermédio que vem assim do mais antigo né? Mais velho. A gente não se envolveu... a gente se envolve com os trabalhos do artesanato né?! Isso puxou nóis pro lado da cidade... que o artesanato a gente construía lá, fazia lá... só que não tinha a venda. Então a gente preferia em busca da cidade, prá consegui vende, né? Então a gente veio vindo, foi conhecendo Caxias do Sul, Farroupilha, Bento Gonçalves... e a gente foi sabendo né? Não por intermédio de... de documento né, mais assim sabendo que existia época atrás, indígena nesse local aqui né? (E1A, 12/04/2015, p.1).

Segundo relato do Entrevistado 1B (2015), questionado sobre o início do acampamento em territórios entre as bacias dos rios Taquari-Antas e Caí, ele responde "Eu na verdade, comecei a acampá ali em... acho que em 95 acho" (E1B, 15/05/2015, p.3). Supōe-se que as vivências nas áreas de Caxias do Sul e Farroupilha eram cotidianas na vida dos Kaingang. Para corroborar com os dados do relato com base na memória indígena, bem como tomar os anos de 1999 e 2000 como período da intensificação do retorno dos Kaingang para tradicionais territórios que atualmente se encontram na jurisdição do município de Caxias do Sul temos o seguinte documento:

0 presente procedimento administrativo foi instaurado em 15 de fevereiro de 2000, a partir da notícia veiculada ao Jornal O Pioneiro, edição de 17 de agosto de 1999, a cerca da existência de indígenas Kaingang acampados na área da estação Rodoviária de Caxias do Sul [...] Considerando que o objeto do presente procedimento passou a ser edificação de moradias para os indígenas que inicialmente estavam acampados na área da Estação Rodoviária de Caxias do Sul, posteriormente transferindo-se para área particular no Município de Farroupilha (DESPACHO DE ARQUIVAMENTO, 2009, p. 2).

A partir do relato do Entrevistado 1A (2015) aponta-se que o acampamento no município de Farroupilha por parte dos Kaingang dá-se pelo "gosto" construído socialmente pelo grupo.

E aí a gente gostou mais e veio pra Farroupilha, acampemo... ali perto da... do acampamento... até hoje tem gente acampada. E fomo ficando ali, trabalhando com o artesanato... e foi... fumo pressionado pelo município, prefeitura né? E fomo chegando até um diálogo assim de... de... um acordo (E1A, 12/04/2015, p.1).

Considerando os estranhamentos e julgamentos culturais que grupos distintos atribuem uns aos outros, "gostar" poderia ser um motivo não plausível e insustentável na visão da sociedade não indígena. No entanto, segundo Geertz (1978) o homem é um animal amarrado a teias de significados que ele mesmo teceu. Sendo a cultura de um grupo suas teias, outro grupo distinto não consegue estabelecer ou compreender certos atos.

O conceito de cultura que eu defendo, e cuja utilidade os ensaios abaixo tentam demonstrar, é essencialmente semiótico. Acreditando, como Max Weber, que o homem é um animal amarrado a teias de significados que ele mesmo te- 
ceu, assumo a cultura como sendo essas teias e a sua analise; portanto, não como uma ciência experimental em busca de leis, mas como uma ciência interpretativa, á procura do significado. É justamente uma explicação que eu procuro, ao construir expressões sociais enigmáticas na sua superfície. Todavia, essa afirmativa, uma doutrina numa cláusula, requer por si mesma uma explicação (GEERIZ, 1978, p.15).

Tomando como base as constatações de Geertz (1978), o "gosto" Kaingang está sob a ótica cultural tecida pelos indivíduos que a compōem. A estranheza cultural por parte dos não indígenas deve-se pela ausência de uma interpretação semiótica.

Outro dado sobre a presença Kaingang no local no período de 1998 ou 1999 e também para demonstrar as negociaçōes realizadas entre indígenas e os órgãos públicos que também se encontra no Trabalho Técnico Social (2008) que informa o seguinte:

A demanda deste projeto é proveniente de uma situação social de conflito decorrente da instalação de um acampamento indígena, em propriedade privada no Município de Farroupilha, há cerca de aproximadamente 10 anos, para a qual foi necessária a busca de uma solução de assentamento (TRABALHO TÉCNICO SOCIAL, 2008, p 24).

Nota-se que uma relação de negociações iniciou entre a prefeitura municipal e o grupo Kaingang. No relato do Entrevistado 1A (2015), temos:

Isso chegamo um ponto de... um grupo em si no início era um grupo... só de administração... porque vinha um no local né? (inaudível?)... de costume do índio memo né? E... foi colocado né... um representante, um cacique que se responsabilizou, se comprometeu como é até hoje né? Que é o cacique que se compromete né... que resolve dentro da comunidade né? Junto de suas lideranças... daí comecemo a se envolve com o branco a se cruzar com o branco né? A fazê acordo né? Fazê acordo né... e fumo permanecendo aí... (E1A, 12/04/2015, p.1).
No documento Comissão de Planejamento Parecer nº 698/2012 (2012) contém parte de uma carta destinada ao Governo do Estado do Rio Grande do Sul em que está descrito, pelos próprios Kaingang, parte de sua historicidade. Conforme segue:

A carta descreve uma síntese da história recente da tribo, que andou errante e abrigou-se em lonas, até ser autorizada pela Prefeitura de Farroupilha a fixar-se na área em que está ocupando. Lá, construíram um prédio de madeira para abrigar uma escola e, através da Assistência Social de Farroupilha, receberam alguns equipamentos para a cozinha (COMISSĀO DE PLANEJAMENTO Parecer nㅇ6 698/2012, 2012, p.1).

A informação apresentada remonta as movimentaçōes Kaingang em "andou errante e abrigou-se em lonas" e também a questão de negociação e fixação no município de Farroupilha. Ao analisarmos este processo de negociação entre Lideranças Kaingang e Prefeitura Municipal de Farroupilha pode-se remeter ao que Barth (2000) tece sobre as concepçōes de fronteiras étnicas. Segundo o autor, as fronteiras se atravessam entre si em um processo de interação social estável, onde muitas vezes, a fronteira étnica faz os grupos conviverem em uma constante dicotomia. Aplicando ao caso citado, supomos que para os Kaingang o "envolve com o branco" é uma interação necessária que fortalece o ser Kaingang; enquanto que, para a Prefeitura Municipal de Farroupilha a coerência com a Constituição Federal de 1988 concretiza o papel deste órgão público.

Bem, como famílias, como tem uma família é que começou o trabalho, começou a luta, começou é se apresentando, se identificando com o município né? $\mathrm{E}$, após isto vem outras famílias que vai dá continuidade de... de outras famílias, é se aproximarem pra cá, morarem pra cá, viverem pra cá né? Bem, como hoje os próprios indígenas são é... politicamente falando, eles votam no município, vivem no município né? São cidadãos farroupilhense no dia de hoje. Então eu vejo que a respeito dos costumes [...] (E3, 15/05/2015, p.4). 
Segundo a atual liderança da Terra Indígena Pó Nãnh Mág, as famílias foram compostas de homens da comunidade de Guarita que se casaram com mulheres de Tenente Portela. As famílias costumavam circular bastante seja pelas áreas indígenas como Ligeiro, Carreteiro, Cacique Doble, Nonoai, Campo do Meio ou pelas cidades de Gramado, Farroupilha, Caxias do Sul e Bento Gonçalves fazendo sempre trajetórias de caminhadas longas vendendo o artesanato ou simplesmente circulando em trabalhos paralelos (DIÁRIO DE CAMPO, 06/02/2014). Neste sentido, temos o seguinte relato:

Lá em Tenente Portela, na Terra Indígena de Guarita. Primeiro veio os meu tio pra cá, tavam acampado aí em Farroupilha e fazia anos já que eles viviam nessa... nesse trajeto vendendo os artesanato deles. Minha mãe veio pra cá também e daí eu vim pra cá também e é isso, vendendo o artesanato aí que na comunidade grande não era fácil, tem muitos indígenas e pouco espaço. Me adaptei na venda de artesanato e até hoje vivo disso... Então cheguei aí, formemo a comunidade né? (E2, 15/05/2015, p. 1).

No registro do Entrevistado 3 (2015) aponta-se o seguinte:

Eu casei com uma índia, uma mulher de Nonoai... então... em Nonoai ela... hã... ali na década de 90 mais ou meno, mais ou meno se espalharam muitos indígenas se vivendo em... tantas formas né? [...]Então aconteceu toda essas criação de acampamento, enfim de comunidade indígena e hoje a gente tem todo esse... essa... esses laços familiar né? Mas, eu acho que... eu acredito que todos nóis, todos nóis, já mais velho que temos família né? Nós temos todo o conhecimento das outras comunidades, não só dessa região, mas quantas outras, as demais comunidade toda Guarita né? (E3, 15/05/2015, p.8).

O registro contido no Trabalho Técnico Social (2008, p.25) apresenta o seguinte: "Quanto a Procedência: As famílias deste grupo de indígenas são procedentes de Tenente Portela, Cacique Doble, Benjamin Constante, Charrua, Nonoai,
Passo Fundo". O dado apontado confere com o que os Kaingang relatam sobre sua procedência e seu passado. Ou seja, ao observarmos a historicidade das outras terras indígenas, conforme anteriormente abordado, constata-se que a Terra Indígena Pó Nãnh Mág encontra-se ligada a estas.

Também, segundo o relato do Entrevistado 1A (2015), temos "E sobre o artesanato... uma coisa né... até aqui meu companheiro tá fazendo algum... as crianças vão correndo e vão se interessando e um dia vão fazê também né? E... a liderança isso é... cultura né?" (E1A, 12/04/2015, p. 1).

Atualmente existe um outro espaço no município de Farroupilha ocupado por dissidências da Terra Indígena Pó Nãnh Mág. A nomenclatura desta aldeia é Terra Indígena Ka Mág, que segundo os Kaingang do local tem relação com uma grande árvore que se encontra no local (DIÁRIO DE CAMPO, 28/10/2016). Segundo Daniel Gonçalves (capitão) fora realizada uma licitação para a compra da área e esta era a mais barata, ela possui 22 hectares de terra (14 de área e 8 de mata densa). No local moram seis famílias, 3 famílias junto com a do Capitão Neri Ribeiro em uma casa e as demais famílias em outra casa. Há em torno de 7 ou 8 crianças que moram na Terra Indígena $K a$ Mág e estudam na Escola Municipal de Ensino Fundamental Padre Vicente Bertoni (DIÁRIO DE CAMPO, 23/09/2016).

$\mathrm{Na}$ atualidade, a maioria dos indígenas tem trabalhos fixos ou temporários. As atividades remuneradas se inserem nas demandas econômicas da região de jurisdição dos municípios de Caxias do Sul, Farroupilha e Bento Gonçalves onde predomina indústrias de malhas, comércio de roupas e produçōes em vinícolas (DIÁRIO DE CAMPO, 06/02/2014).

É, o acampamento principalmente nas comunidade, os acampamento que nós fazia antes que nóis ia mais no interior, a gente não tem, por causa que trabaiemo em Caxias, trabaiemo em Caravagio, trabaiemo em Gramado, o pessoal vai 
pra Gramado, daí eles vão lá e alugam já uma casa né? (E1A, 15/05/2015, p.12).

No entendimento Kaingang, pobreza poderia ser considerada como a ausência de crença, segurança, de espaço adequado para realizar danças e curas tradicionais. Pobreza é mais ausência do que impossibilidade de viver sua cultura (GARLET, 2010). Esta relação de pobreza, muito diferente da sociedade capitalista, é apresentada no relato:

Eu aprendi a vida Kaingang de... (inaudível)... que não de muito interesse, né? Ele qué vivê. Ele tendo... uma casa mais ou menos pá sossega, tendo comida, um poquinho de dinheiro, não muito né? Acho que assim... e convivendo... que vai aumentando meus animalzinho (E1A, 12/04/2015, p. 1).

Ao falar dos pinheiros a nossa esquipe de pesquisa, um indígena tinha outra explicação para identificar a idade, o macho e a fêmea da espécie. Isto é, os Kaingang identificam o macho com uma tinta roxa que ele produz, item que a fêmea não o faz. Ainda caminhando, nos mostrou a Korfé o equivalente à Urtiga e o Angorô que é samambaia tradicionalmente utilizada como salada pelos Kaingang. $\mathrm{O}$ interessante é que eles não se alimentam dos exemplares que estão próximos às estradas, pois entram mais em contato com os poluentes (DIÁRIO DE CAMPO, 28/10/2016).

Os Kaingang possuem elementos culturais enraizados nas decisões força de seu processo histórico. Suas movimentações pelo território e opçōes de fixaçōes são regradas pelos entrelaces culturais desta sociedade e tais aspectos podem ser vistos na atualidade nas Terras Indígenas Jamã Tÿ Tãnh, Pó Nãnh Mág e Ka Mág e como povos distintos e de direitos, devem ter sua história e cultura respeitada como direitos humanos.

\section{Consideraçōes finais}

O projeto colonialista e desenvolvimentista posto em marcha no Brasil Meridional e que diretamente atingiu o tradicional território Kaingang inega- velmente acarretou mudanças estruturais significativas. No entanto, como visto ao longo deste texto, este grupo reagiu e orquestrou os elementos novos do projeto colonialista pelos parâmetros sócio-culturais Kaingang. Sendo assim, com base na investigação desenvolvida constata-se que ao contrário do pensamento colonizar difundido as relações de contato não minimizou os etnoconhecimentos indígenas.

Os Kaingang apresentam-se na atualidade com uma teia de significados imbricados entre o passado e o presente e, não menos importante, orquestram suas posiçōes e atividades cotidianas a partir deste emaranhado sócio-cultural. São exemplos da língua no que se refere a nominação das comunidades indígenas, as relaçōes sociopolítica com o território em tradicionais áreas das bacias hidrográficas, o sistema simbólico e interaçōes entre homem e o ambiente, bem como as continuidades dos traços culturais Kaingang analisados neste texto.

\section{Referências}

ALMEIDA, L. K; et. al. 2009. O consumo de bebidas alcoólicas entre os Kaingang do Rio Grande do Sul. In: SILVA, Gilberto Ferreira da; PENNA, Rejane; CARNEIRO, Luiz Carlos da Cunha (Org.). RS Índio: cartografia sobre a produção do conhecimento. Porto Alegre: EDIPUCRS, p. $144-154$.

BARTH, F. [1969] 2000. Os grupos étnicos e suas fronteiras. In: BARTH, F. LASK, T. (org.). 0 Guru, o iniciador e outras variaçōes antropológicas. Rio de Janeiro: Contracapa, p. 25-67.

CABRAL, L O. 2007. Revisitando as noçōes de espaço, lugar, paisagem e território, sob uma perspectiva geográfica.

Revista de Ciências Humanas. Florianópolis, v. 41, n. 1 e 2, p. 141-155, abr./out.

CAPRA, F. 2006. A teia da vida: uma nova compreensão científica dos sistemas vivos. São Paulo: Cultrix.

CASTRO, E. V. 2006. No Brasil, todo mundo é índio, exceto quem não é. Entrevista. In: RICARDO, B.; RICARDO, F. (Eds.). Povos Indígenas no Brasil: 2001-2005. São Paulo: ISA, p. 41-49. Disponível em: https://pib.socioambiental.org/files/file/PIB_institucional/No_Brasil_todo_mundo_\%C3\%A9_\%C3\%ADndio. pdf. Acesso em: 21 set. 2016. 
COMISSĀODEPLANEJAMENTO. 2012. Parecerno 698/2012 Processo SE № 81.207/19.00/11.04. Manifesta-se favorável à criação de escola estadual indígena de ensino fundamental na Aldeia da Comunidade Indígena Pãnnoh, no Bairro Vicenza, no município de Farroupilha. Governo do Estado do Rio Grande do Sul, Porto Alegre.

DESPACHO DE ARQUIVAMENTO. 2009. 05 de fevereiro de 2009. In: INQUÉRITO CIVIL MINISTÉRIO PÚBLICO FEDERAL DE CAXIAS DO SUL Índios e minorias.

DIÁRIO DE CAMPO de 06/02/2014. Visita à Terra Indígena Pó Nãnh Mág. Farroupilha/RS. [XXXXX] 08 fev. 2014. 3 p.

DIÁRIO DE CAMPO de 03/12/2015. Pesquisa de Campo na Terra Indígena Jamã Tÿ Tãnh. Estrela/RS. [XXXXX] 03 dez. 2016, 2 p.

DIÁRIO DE CAMPO de 14/01/2016. Pesquisa de Campo na Terra Indígena Jamã Tÿ Tãnh. [XXXXX] 14 jan. 2016. $6 \mathrm{p}$.

DIÁRIO DE CAMPO de 07/07/2016. Pesquisa de Campo na Terra Indígena Jamã Tÿ Tãnh. [XXXXX] Lajeado: Univates. 07 jul. 2016.5 p.

DIÁRIO DE CAMPO de 10/08/2016. Pesquisa de Campo na Terra Indígena Jamã Tÿ Tãnh. [XXXXX] 10 ago. 2016. $4 p$.

DIÁRIO DE CAMPO de 28/10/2016. Visita à Terra Indígena Pó Nãnh Mág. Farroupilha/RS. [XXXXX] 28 out. 2016. 9 p.

E1A - Entrevistado 1A: relato [12 abr. 2015, 9 p.]. Terra Indígena Pó Nãnh Mág, Farroupilha/RS. Entrevistador: Marina Invernizzi. Lajeado (RS): s.e., 2015. Gravação em gravador digital. [XXXXX]

E1B - Entrevistado 1B: relato [15 mai. 2015, 12 p.]. Terra Indígena Pó Nãnh Mág, Farroupilha/RS. Entrevistador: Marina Invernizzi. Lajeado (RS): s.e., 2015. Gravação em gravador digital. [XXXXX]

E2 - Entrevistado 2: relato [15 mai. 2015, 12 p.]. Terra Indígena Pó Nãnh Mág, Farroupilha/RS. Entrevistador: Marina Invernizzi. Lajeado (RS): s.e., 2015. Gravação em gravador digital. [XXXXX]

E3 - Entrevistado 3: relato [15 mai. 2015, 12 p.]. Terra Indígena Pó Nãnh Mág, Farroupilha/RS. Entrevistador: Marina Invernizzi. Lajeado (RS): s.e., 2015. Gravação em gravador digital. [XXXXX]

EA e EB - Entrevistado A e Entrevistado B: relato [10 fev. 2016, 9 p.]. Terra Indígena Jamã Tÿ Tãnh, Estrela/RS. Entrevistador: Juciane da Silva. Estrela (RS): s.e., 2016. Gravação em gravador digital. [XXXXXX]

EC - Entrevistado C: relato [17 mar. 2011, 3p]. Terra Indígena Linha Glória, Estrela/RS. Entrevistador: Juciane da Silva.
Estrela (RS): s.e., 2011.Gravação em máquina digital 6.0 Mega Pixels. [XXXXX]

EF - Entrevistado F: relato [28 jul. 2016, 14 p.]. Terra Indígena Jamã Tÿ Tãnh, Estrela/RS. Entrevistadores: Ernesto Neto, Fabiane da Silva Prestes, Juciane da Silva. Lajeado (RS): s.e., 2016. Gravação em gravador digital. [XXXXX]

INVERNIZZI, M. 2015. Historicidade Kaingang na Terra Indígena Pó Nãnh Mág, em Farroupilha/RS. 2015, 120 f, Monografia (Graduação) - Curso de Licenciatura em História, Centro Universitário Univates, Lajeado

GARLET, M. 2010. Entre cestos e colares, faróis e parabrisas: crianças Kaingang em meio urbano. 2010. 266 f. dissertação (mestrado) - Serviço Social, PUCRS, Porto Alegre.

GEERTZ, C. 1978. A interpretação das culturas. Rio de Janeiro: Zahar.

LITTLE, P E. 1994. Espaço, memória e migração. Por uma teoria de reterritorialização. Textos de História. Revista de Pós-Graduação em História da UNB. Brasília, v.2, n.4, p.5-25.

2002 Territórios sociais e povos tradicionais no Brasil: por uma antropologia da territorialidade. Série Antropologia. v.1, no 322 , p.1-32.

ROSA, R. R. G. 2005. O território Xamânico Kaingang vinculado às Bacias Hidrográficas e à Floresta de Araucária. Cadernos do LEPAARQ, v. 2, n. 04, p.101-117.

SCHWINGEL, K. et al. (Orgs.). 2014. Jamã Tý Tãnhn. Ig Vênh vêj Kaingag. Morada do Coqueiro. Jeito de viver Kaingang. São Leopoldo: Oikos.

SEEGER, A.; CASTRO, E. B. V. 1979. Terras e Territórios Indígenas no Brasil. Encontros com a Civilização Brasileira. Rio de Janeiro, p.101-109.

SIDEKUM, A. 2003. Alteridade e interculturalidade. In: (org.). Alteridade e multiculturalismo. Ijuí: Ed. Unijuí, p.233-295.

SILVA, J. B. S. 2011. Territorialidade Kaingang: um estudo histórico da Aldeia Kaingang Linha Glória, Estrela/RS. 2011. 125 f. Graduação (Monografia) - Curso de História, Centro Universitário UNIVATES, Lajeado.

2016. "Eles viram que o índio tem pode, né!" Protagonismo Kaingang da Terra Indígena Jamã Tÿ Tãnh/Estrela diante do avanço desenvolvimentista de uma Frente Pioneira. 257 f. Dissertação. Pós Graduação em Ambiente e Desenvolvimento, Centro Universitário UNIVATES, Lajeado

SILVA, J. B. S.; LAROQUE, L. F. S. 2012. A história dos Kiangang da Terra Indígena Linha Glória, Estrela, Rio Grande do Sul/Brasil: sentidos de sua (re) territorialidade. Socie- 
dade e Natureza. Uberlândia. V. 24, n.03, p. 435-448, set/ dez. 2012. Disponível em: http://www.seer.ufu.br/index. php/sociedadenatureza/article/view/15008. Acesso em: 06 out. 2015.

TRABALHO TÉCNICO SOCIAL 08 de maio de 2008. In: INQUÉRITO CIVIL MINISTÉRIO PÚBLICO FEDERAL DE CAXIAS DO SUL Índios e minorias. 2009.

TOMMASINO, K. 2001. Os Sentidos da Territorialização dos Kaingang nas Cidades. Curitiba, p.01-15 (digitado).

_._. 2004. Cosmologia Kaingang e suas práticas rituais. In: _____; MOTA, Lucio Tadeu; NOELLI, Francisco Sil- va. Novas contribuiçōes aos estudos interdisciplinares dos Kaingang. Londrina: Eduel, p. 268-284.

2005. Considerações etnológicas a partir de dois conceitos Kaingang: Ga e Krĩ. In: VI Reuniāo de Antropologia Del Mercosur. Montevideo, 17 p.

WOLF, S. 2012. Paisagens e sistemas de assentamento: um estudo sobre a ocupação humana pré-colonial na Bacia Hidrográfica do Rio Forqueta/RS. 187f. Dissertação (Mestrado) -Programa de Pós-Graduação em Ambiente e Desenvolvimento, Centro Universitário UNIVATES, Lajeado.

\section{Marina Invernizzi}

Atualmente é mestranda no Programa de Pós Graduação em Ambiente e Desenvolvimento - Univates com vínculo de bolsista PROSUP/CAPES dedicação exclusiva. Possui graduação em História pelo Centro Universitário Univates (2015).

\section{Juciane Beatriz Sehn da Silva}

Possui Graduação em História (2011) e Mestrado em Ambiente e Desenvolvimento (2016) pelo Centro Universitário Univates. É doutoranda no Programa de Pós-Graduação em Ambiente e Desenvolvimento, da Universidade do Vale do Taquari - Univates. Atua como professora na Educaçāo Básica.

\section{Luís Fernando da Silva Laroque}

Possui graduação em Estudos Sociais pela Universidade do Vale do Rio dos Sinos (1992), graduação em História pela Universidade do Vale do Rio dos Sinos (1996), mestrado em História pela Universidade do Vale do Rio dos Sinos (2000) e doutorado em História pela Universidade do Vale do Rio dos Sinos (2006). Atualmente é professor da Universidade do Vale do Taquari - Univates e professor da rede de ensino do Estado do Rio Grande do Sul. 